\title{
Simulation of groundwater fluctuation in fracture-zone landslides
}

\author{
Akhilesh Kumar KARNA ${ }^{\text {a)* }}$, Hiroyuki NAKAMURA ${ }^{\text {b) }}$ and Katsushige SHIRAKI ${ }^{\text {) }}$
}

\begin{abstract}
Landslide is one of the major geotechnical problems in the mountainous regions. Pore water pressure is one of the main factors which affect the shear strength of the soil at the slip surface, thereby making the slope more unstable. Therefore, it is necessary to predict groundwater table to forecast the stability of a slope. Further, in order to understand the groundwater fluctuation, it is necessary to know the hydraulic properties of the landslide soil. Hydraulic conductivity and soil-water retention function of landslide material are the two most important factors determining the seepage flow characteristics. As the fracture-zone landslides are highly discontinuous due to existence of cracks through which major groundwater flow occurs, the use of experimentally measured soil hydraulic parameters are quite limited. This article attempts to find a suitable method to estimate these properties using the rainfall and groundwater level measured in-situ using finite element method. In order to achieve this, parametric analysis was done considering multilayered soil matrix. The result of analysis was applied to an actual landslide and it was found that agreeable groundwater fluctuation can be obtained by assuming homogeneous soil properties with multilayered system.
\end{abstract}

Key words : fracture-zone landslide, groundwater level prediction, seepage flow simulation, soil hydraulic properties

\section{Introduction}

Mountainous countries like Nepal suffer economic loss and the loss of human life due to the landslides every year. Successful prediction of landslide movement can help to reduce the adverse consequences of landslide. The prediction of groundwater level is essential to forecast the stability of landslide. Many statistical models have been proposed by researchers to forecast the landslide stability. Jacob et al. (2003) has cited some research works of Caine (1980), Cannon and Ellen (1985), Wieczorek (1987), and Wieczorek et al. (2000). In Japan, statistical formulas are used to calculate critical rainfall, based on which degree of landslide hazard is determined. The above mentioned models do not consider soil properties and the physical process involved in the landslide movement.

The fluctuation of groundwater level depends on a number of geotechnical and hydrological factors, including soil permeability, initial position of the groundwater level, intensity and duration of rainfall, amount of antecedent rainfall etc. Further, the most important factor influencing the seepage flow, the hydraulic conductivity of soil, is a challenging soil hydraulic property to describe because it can change many orders of magnitude over short distances (Sobieraj et al., 2003). The geologic materials are almost always heterogeneous. The small-scale features being immaterial at a larger scale (Vogel et al., 2003), hydraulic properties measured with more and more precision at few places

\footnotetext{
* corresponding author

a) United Graduate School of Agriculture, Tokyo University of Agriculture and TechnolUnited ogy

3-5-8 Saiwai-cho, Fuchu-shi, Tokyo, 183-8509, Japan

b) Tokyo University of Agriculture and Technology, Tokyo
}

will not sufficiently represent the whole landslide. Consequently, indirect estimation of soil properties from field data may be more relevant, especially for fracture zone landslides where heterogeneity is high. Empirical methods can be applied to predict soil hydraulic properties using soil porosity, particle size distribution data etc. Soil-water retention being relatively easier to compute experimentally than the soil hydraulic conductivity, the later can be predicted by various models. Among them, Brooks and Corey (1964), van Genuchten (1980), Burdine (1953), Mualem (1976) are a few models which are used to predict the hydraulic conductivity from the pore size distribution and water retention data.

As the groundwater flow mostly occurs through cracks in the fracture zone landslide the soil hydraulic properties obtained experimentally may not represent the whole landslide area. Using such data directly in the seepage analysis may not yield suitable results. So, the present research attempts to find the hydraulic properties of soil using the rainfall data and the groundwater level in the field.

To estimate the soil properties, various field data such as rainfall, groundwater level, borehole log etc. can be used. However, the first step will be to comprehend the influence of different soil hydraulic properties to the seepage flow.

Recently, there has been many research works related to seepage analysis in the landslide area using numerical methods with the advent of numerous commercially available softwares.

Fell et al. (1991) suggested a model for prediction of 
piezometric levels. However, this model does not consider unsaturated soil properties. So far few simulation works regarding seepage flow in the landslide areas has been done. Tsaparas et al. (2002) investigated the effect of antecedent rainfall (considering assumed rainfall scenarios), and initial pore water pressure on the stability of slope with different hydraulic conductivities. Gasmo et al. (2000) analyzed a shallow residual soil slope and observed that it was quite difficult to quantify the amount of infiltration. Cho et al. (2001), Ng et al. (1998) investigated the effect of different hydraulic parameters in the landslide stability. Further research work is necessary to find a suitable way to forecast the groundwater fluctuation based on the relationship between different parameters and the groundwater fluctuation in the landslide areas.

The present research work focuses on the fracture zone landslide. In such landslide most of the groundwater flow occurs through cracks and fissures. The flow in fractured media and macroporous soil are termed as preferential flow. Preferential flow was defined by Hendrickx et al. (2001) as 'all phenomena where water and solutes move along certain pathways while passing a section of the porous matrix'. Thus, to address the seepage flow in the fracture zone landslides, it is necessary to understand the preferential flow.

Duggid et al. (1977), Or et al. (2003), El-Naqa (2001) analyzed the conductivity of fractures considering flow through cracks only. Greco (2002) analyzed flow through swelling soil with shrinkage cracks. Simunek et al. (2003) has done extensive review and comparison of different models related to preferential flow and transport. Durner et al. (1999), Simunek et al. (2003), Or et al. (2003) have found that both the retention curve and hydraulic conductivity curves for the fracture zone are steep in the unsaturated zone.

It is difficult to incorporate macropores such as cracks into the finite element analysis of seepage flow. As such, the fractured rock layer was considered as homogenous soil matrix and the analysis was done to find the parameters which can suitably represent the landslide matrix. The present analysis was done using SEEP/W, a software for finite element analysis of seepage flow. The two dimensional geometry of the model, boundary condition, initial condition, soil hydraulic properties are the input parameters for the seepage analysis. The final aim of the study is to find a method to estimate the suitable soil hydraulic parameters for a landslide which satisfy the groundwater fluctuation using transient seepage flow analysis. The analysis is done by examining the effect of various parameters affecting the seepage flow.

\section{Research methodology}

According to Koide (1955) landslides can be divided into 3 categories based on the geology of the landslide areas as tertiary landslide, fracture-zone landslide and hydrothermal zone landslide. Furuya (1982) explained about the characteristics and mechanism of a typical landslide in fracture zone in Sambagawa belt. Many landslides in the Sambagawa belt of Shikoku Island show similar characteristics. While the landslides in fracture zone differ from place to place, a typical landslide consists of top residual or colluvial layer consisting of clay mixed rock fragments, middle layer consisting of highly weathered and fractured rock and slightly weathered to non-weathered rock layer at the bottom.

The landslides in the fracture zone are quite complex, however. Some of the landslides were analyzed for the actual geometry and simplified geometry assuming the same hydraulic properties and rainfall condition. The results were found to be very much similar So, for the present analysis a simplified geometrical section was considered for both the parametric analysis and the analysis of real landslide. The Yuzurihara landslide, which consists of colluvium and highly fractured rock and slightly fractured rock layers as the depth increases, can be considered as a typical landslide in the fracture zone. The detail of the case study is presented in the section 4 .

\subsection{Governing equations}

Water flow in unsaturated or partly saturated soils can be described with the Richards' equation (Richards, 1931) as

$$
C \frac{\partial h}{\partial t}=\frac{\partial}{\partial z}\left(K \frac{\partial h}{\partial z}-K\right)
$$

where, $h=$ soil-water pressure head, $t=$ time, $z=$ soil depth, $K$ =hydraulic conductivity, $C$ =soil-water capacity (approximated by the slope of water retention curve, $d \theta / d h$ ).

The SEEP/W software uses the Richards' equation in the following form for the two dimensional transient flow:

$$
\frac{\partial}{\partial x}\left(k_{x} \frac{\partial H}{\partial x}\right)+\frac{\partial}{\partial y}\left(k_{y} \frac{\partial H}{\partial y}\right)+Q=\frac{\partial \theta}{\partial t}
$$

where, $H=$ total head, $k_{x}, k_{y}=$ hydraulic conductivity in the $x$ and $y$-direction respectively, $Q=$ applied boundary flux, $\theta=$ volumetric water content, $t=$ time

Since both the hydraulic conductivity and soil-water 
retention are the function of head, Eqn.(2) can be rewritten as:

$$
\frac{\partial}{\partial x}\left(f_{k x}(H) \frac{\partial H}{\partial x}\right)+\frac{\partial}{\partial y}\left(f_{k y}(H) \frac{\partial H}{\partial y}\right)+Q=\frac{\partial f_{\theta}(H)}{\partial t}
$$

where, $k_{x}=f_{k x}(H), k_{y}=f_{k y}(H), \theta=f_{\theta}(H)$ correspond to the soil hydraulic properties. In the present analysis, the hydraulic conductivity and soil-water retention functions were assumed and groundwater fluctuations were analyzed for different slope, rainfall and boundary conditions. In case of soil properties, main consideration was the saturated and residual hydraulic conductivities $\left(k_{s}\right.$ and $k_{r}$ ) and saturated and residual soilwater content $\left(\theta_{s}\right.$ and $\left.\theta_{r}\right)$ respectively. Parametric analyses were done for single layer homogeneous soil, two-layered and three layered matrix systems as explained below.

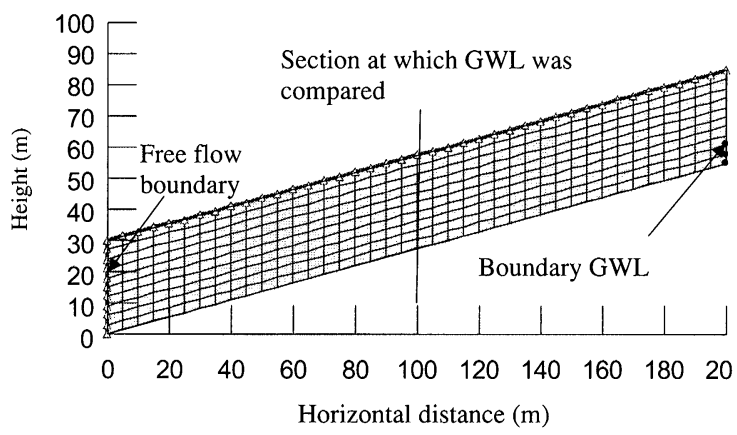

Fig. 1 Geometry and finite element mesh for parametric analysis

Table 1 Parameters used in the analysis

\begin{tabular}{|c|c|c|c|c|c|c|}
\hline \multirow{2}{*}{\begin{tabular}{|l|} 
Parameters \\
Slope
\end{tabular}} & \multicolumn{6}{|l|}{ Values } \\
\hline & \multicolumn{2}{|l|}{$15.4^{\circ}$} & \multicolumn{2}{|l|}{$20.5^{\circ}$} & \multicolumn{2}{|c|}{$25.4^{\circ}$} \\
\hline $\begin{array}{l}\text { Saturated } \\
\text { conductivity } \\
\text { (Fig.2) }\end{array}$ & $\begin{array}{l}2.0 \mathrm{~m} / \mathrm{d} \\
\left(2.3 \times 10^{-3}\right. \\
\mathrm{cm} / \mathrm{s})\end{array}$ & $\begin{array}{l}1.0 \\
(1.2 \times \\
\mathrm{cm} / \mathrm{s}\end{array}$ & $\begin{array}{l}\mathrm{m} / \mathrm{d} \\
\times 10^{-3} \\
\end{array}$ & $\begin{array}{l}0.5 \mathrm{~m} / \mathrm{d} \\
\left(5.8 \times 10^{-4} \mathrm{~cm} /\right.\end{array}$ & & $\begin{array}{l}0.1 \mathrm{~m} / \mathrm{d} \\
\left(1.2 \times 10^{-4} \mathrm{~cm} / \mathrm{s}\right)\end{array}$ \\
\hline $\begin{array}{l}\text { Water } \\
\text { retention } \\
\text { capacity, } \theta_{\mathrm{s}} \text { - } \\
\text { (Fig.3) }\end{array}$ & 0.20 & 0.15 & & 0.05 & & 0.02 \\
\hline $\begin{array}{l}\text { Boundary } \\
\text { head }\end{array}$ & $1 \mathrm{~m}$ rise in & 1 day & $1 \mathrm{~m}$ rise & in 3 days & $1 \mathrm{mr}$ & ise in 7 days \\
\hline Rainfall & $\begin{array}{l}\text { hree types of } \\
\text { Rain-1: } 100 \mathrm{~m} \\
\text { Rain-2: } 100 \mathrm{~m} \\
\text { Rain-3: } 20 \mathrm{mr}\end{array}$ & $\begin{array}{l}\text { ainfall } p \\
\text { am rainf } \\
\text { m rainf } \\
\mathrm{n} / \text { day ra }\end{array}$ & $\begin{array}{l}\text { attern use } \\
\text { all in first } \\
\text { all in first } \\
\text { infall for }\end{array}$ & $\begin{array}{l}\text { ed: } \\
\text { one hour then } \\
\text { one day and } t \\
\text { first five days }\end{array}$ & $\begin{array}{l}\text { n rainf } \\
\text { then } r \text {. } \\
\text { then }\end{array}$ & $\begin{array}{l}\text { all stops. } \\
\text { infall stops. } \\
\text { ainfall stops. }\end{array}$ \\
\hline
\end{tabular}

\section{2 Parametric analysis}

\section{2. 1 Analysis of Single-layer soil matrix}

At first, parametric analysis was done for the conductivity function and the water retention function assuming the matrix to be homogeneous. As the rainfall data are available in terms of days, for convenience 'day' was used as the unit of time instead of SI unit.

For the present analysis different slopes of $200 \mathrm{~m}$ length was used (Fig.1). Hydraulic conductivity and soil-water retention function and input rainfall and boundary head (GWL) at the upstream were varied to produce different scenarios. Table 1 shows the different parameters and their values used in the analysis. In the case of comparing the effect of change in boundary groundwater level the upstream boundary head was varied, however it was kept constant in all the other cases. The downstream boundary was kept as free flow boundary (Fig.1). The initial condition was calculated by applying uniform rainfall of $4 \mathrm{~mm}$ for each scenario to achieve stable hydraulic condition in the mesh elements. The analysis was done for 50 days for each case.

A typical result of groundwater variation with time for four materials with different hydraulic conductivities is shown in Fig.2. Similarly, result of analysis of a

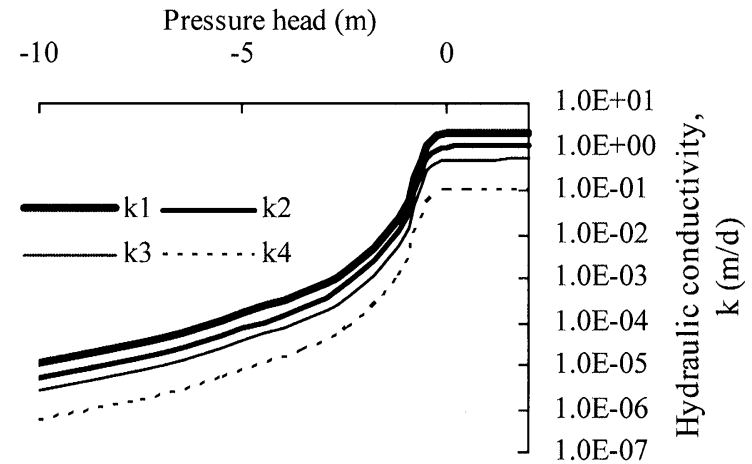

Fig. 2 Hydraulic conductivity functions used in the analysis

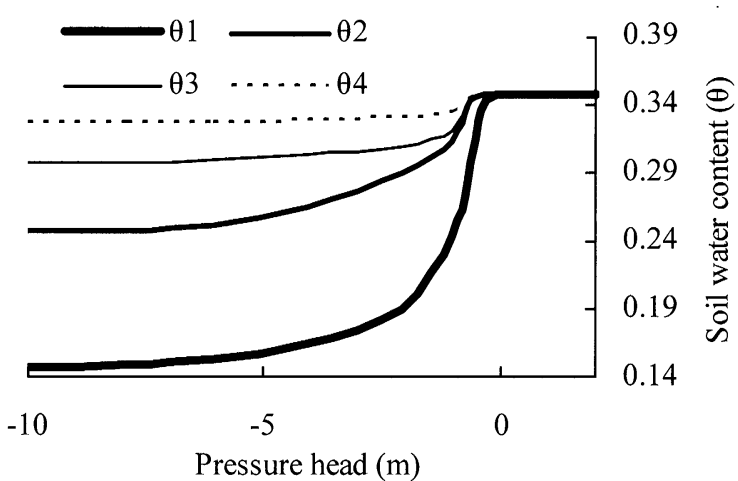

Fig. 3 Soil-water retention functions used in the analysis 
model using different water retention functions is shown in Fig.3. The results of parametric analysis can be summarized in the following points:

-The increase and decrease in hydraulic conductivity curve proportionately results in lowering and raising the groundwater level respectively. A certain time, depending on the soil-water retention function and other factors, after cessation of the rainfall the groundwater falls back to original position. Increase in hydraulic conductivity above $1 \mathrm{~m} /$ day does not produce considerable change in the overall groundwater level in this case. Fig.4 shows comparison between the groundwater levels for four different hydraulic conductivities. For each case, the soil-water retention function is the same and rainfall is $100 \mathrm{~mm}$ in one day. The change in hydraulic conductivity produce the similar result for different rainfall conditions and different slopes. It is due to the fact that when the conductivity is low, the outflow is very little compared to the case when the material has higher conductivity.

-When the difference of saturated and residual water content $\left(\theta_{s}-\theta_{r}\right)$ is reduced the fluctuation of groundwater level becomes faster and higher. Fig.5 shows the fluctuation of groundwater level due to different soil-water retention function for a rainfall of 20 $\mathrm{mm}$ /day for the initial 5 days (Rain3, Table 1).

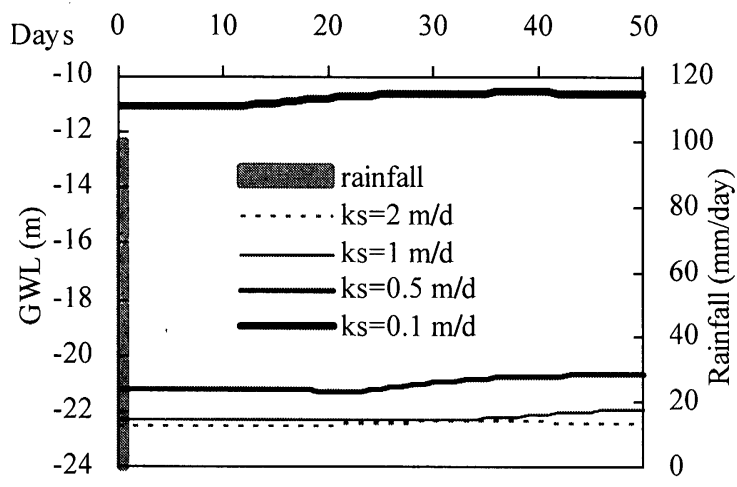

Fig. 4 Fluctuation of groundwater with varying $k$-functions

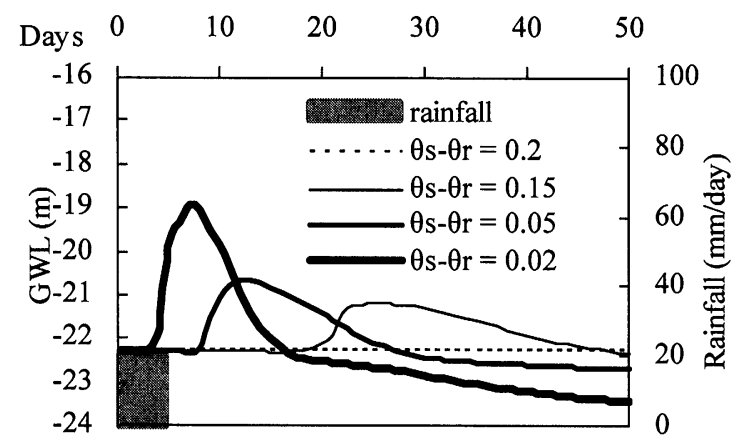

Fig. 5 Groundwater fluctuation with different $\theta$-functions $\checkmark$ When the slope of the water retention curve becomes steeper, the groundwater fluctuates faster and higher similar to the effect of change in the value of $\theta_{s}$ $\theta$.

-When we use upstream boundary condition, the matrix with lower conductivity has less effect of the boundary condition as compared to the matrix with higher conductivity. For example, a rise in boundary head of $1 \mathrm{~m}$ in one week causes $0.26 \mathrm{~m}$ rise in groundwater level in case of high conductivity soil $\left(k_{s}=2.0 \mathrm{~m} /\right.$ day) while the same rise in boundary head causes only $0.03 \mathrm{~m}$ rise in groundwater level for low conductivity soil $\left(k_{s}=0.01 \mathrm{~m} / \mathrm{d}\right)$.

\section{2. 2 Analysis of two-layered matrix}

Hydraulic properties of the top layer of a twolayered matrix (Fig.6) were varied to examine the resulting variation in groundwater level. The properties of lower layer were kept constant. The boundary conditions are the same as explained for the analysis of single layer (Section 2.2.1). Table 2 shows the values of different parameters of top layers used in the analysis. $100 \mathrm{~mm} /$ day of rainfall for initial one day was applied in each case.

The results of the analysis with two layer matrix can be summarized as follows.

-When the conductivity of top layer is high the effect of top layer is negligible. When the conductivity of top layer is low the peak groundwater level becomes

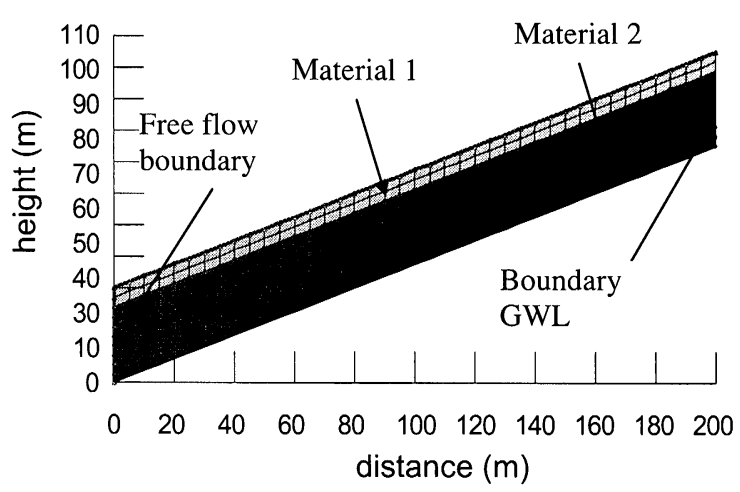

Fig. 6 Two layered arrangement (Saturated conductivities $\boldsymbol{k}_{s 1}$ and $\boldsymbol{k}_{s 2}$ respectively)

Table 2 Parameters used in the analysis

\begin{tabular}{|c|c|c|c|c|}
\hline Parameters & \multicolumn{4}{|l|}{ Values } \\
\hline $\begin{array}{l}\text { Saturated } \\
\text { conductivity }\end{array}$ & $1.0(\mathrm{~m} / \mathrm{d})$ & $0.5(\mathrm{~m} / \mathrm{d})$ & $0.02(\mathrm{~m} / \mathrm{d})$ & $0.01(\mathrm{~m} / \mathrm{d})$ \\
\hline$\theta_{\mathrm{s}}-\theta_{\mathrm{r}}$ & 0.05 & 0.10 & 0.15 & 0.20 \\
\hline depth & $5.7 \mathrm{~m}$ & $6.0 \mathrm{r}$ & & \\
\hline
\end{tabular}


lower and the fluctuation slows down. Fig.7 shows the fluctuation of groundwater with the change in the hydraulic conductivity function of top layer.

—When $\theta_{s}-\theta_{r}$ of the top layer is reduced, the groundwater fluctuation becomes faster (Fig.8). However, when the $\theta_{s}-\theta_{r}$ is higher than 0.1 the difference is negligible.

-When thickness of upper layer is increased the fluctuation of groundwater level becomes slower (Fig.9).

\subsubsection{Analysis of three-layered soil matrix}

For a three layered scenario (Fig.10), we need to consider the effect of the hydraulic properties of the

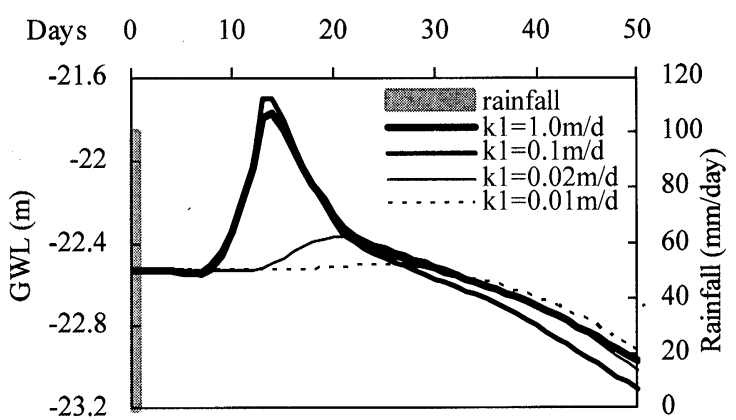

Fig. 7 Variation of groundwater level with the saturated hydraulic conductivity of top layer

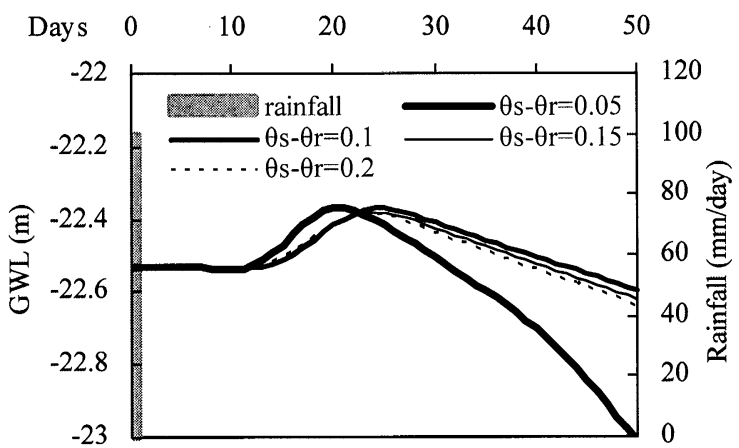

Fig. 8 Variation of groundwater level with the saturated soil-water retention function of top layer

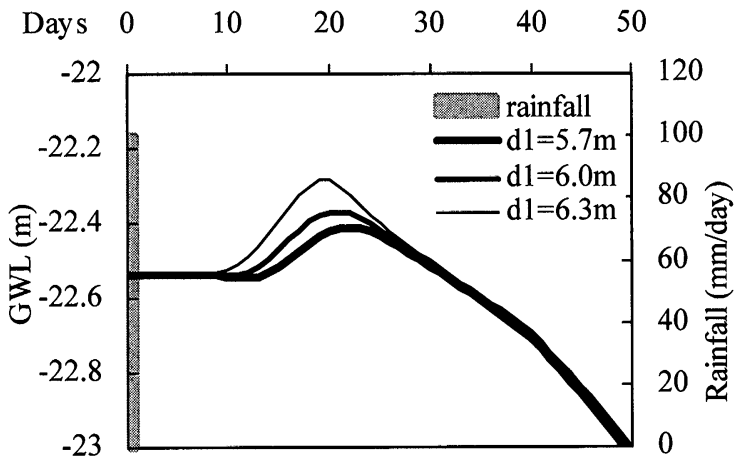

Fig. 9 Change in groundwater level with depth of top layer bottom layer. We considered the depth of the bottom layer, hydraulic conductivity function and the soilwater retention function of the matrix at the bottom layer as the parameters subject to variation in the analysis. In each case rainfall of $100 \mathrm{~mm}$ for initial one day was applied. The analysis was done for 50days in each case. The result of the parametric analysis is summarized below.

The lower the hydraulic conductivity of the bottom level, the higher is the groundwater level. The fluctuation of groundwater also diminishes (Fig.11).

-The variation of $\theta_{s}-\theta_{r}$ of the bottom layer does not affect the groundwater fluctuation significantly.

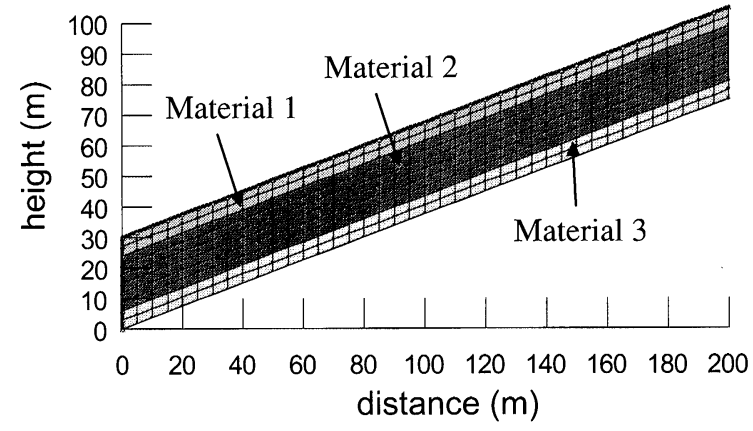

Fig. 10 Three layered arrangement (Saturated conductivities $\boldsymbol{k}_{s 1}, \boldsymbol{k}_{s 2}$ and $\boldsymbol{k}_{s 3}$ respectively)

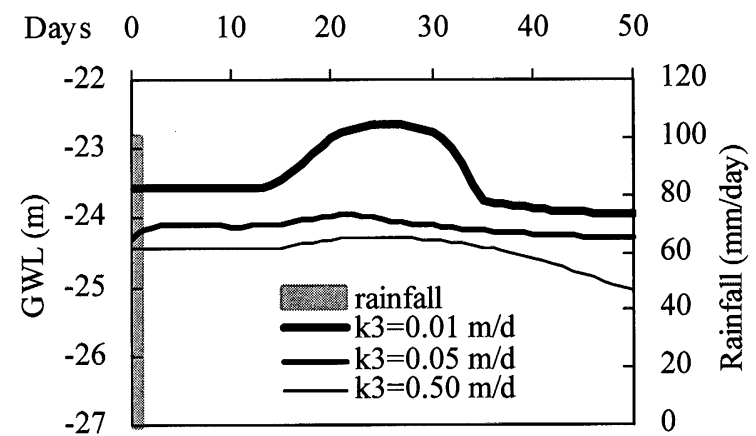

Fig. 11 Variation of groundwater level with the saturated hydraulic conductivity of bottom layer

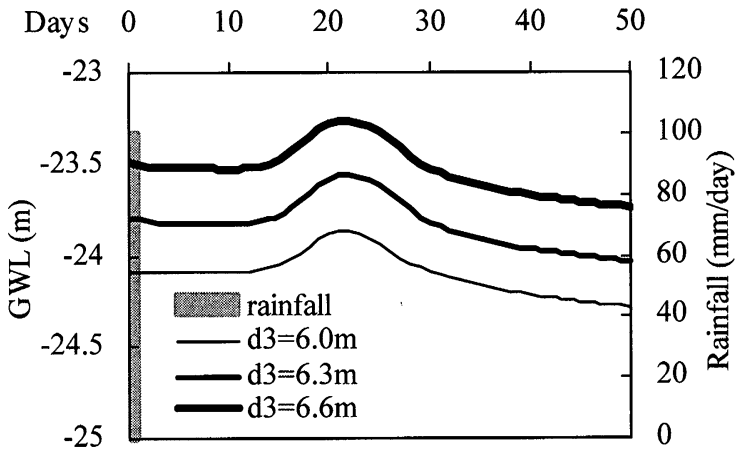

Fig. 12 Variation of groundwater level with the depth of bottom layer 


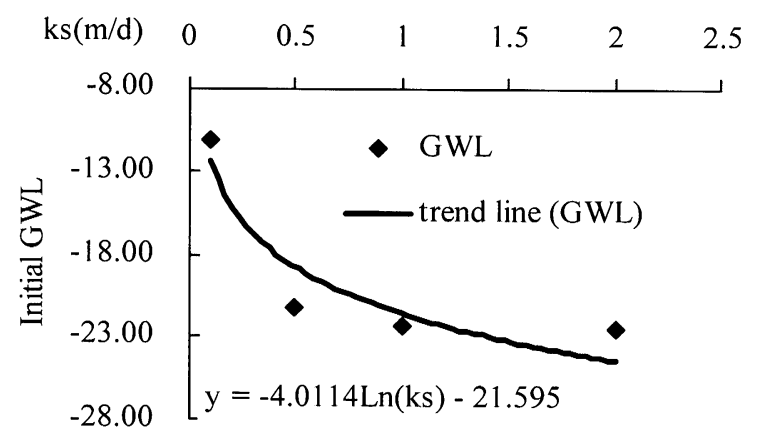

Fig. 13 Variation of initial GWL with respect to saturated hydraulic conductivity (assuming depth $=30 \mathrm{~m}$ )

-As we increase the depth of the bottom layer, the groundwater level as a whole becomes higher. The pattern of fluctuation does not have much effect (Fig.12).

\section{Proposed method for analysis for calculating soil hydraulic properties}

The effect of hydraulic conductivity function for a single layer soil matrix can be explained on the basis of Fig.13. The initial groundwater level determines the overall groundwater level, especially the groundwater level when there is no rainfall for long time. Similarly, from the above results, it is clear that the soil-water retention function affects the fluctuation of groundwater level, namely, a) time for initial rise in the groundwater level, b) time for reaching peak and c) the peak value of groundwater level. Based on this, we can find the appropriate soil parameters for a landslide with uniform matrix by method of iteration if we know the depth of infiltration. For this, we need to vary the hydraulic function roughly and compare the result of calculation with the groundwater level measured at site. In the next step the water retention function has to be varied to compare the fluctuation. The above process needs to be repeated to find the hydraulic parameters which satisfy the measured fluctuation of groundwater level better.

As landslides in the fracture zone are never homogeneous, consisting of more than one layer, it is necessary to use the result of analysis of two-layered and three-layered matrix explained in the previous section. The following case study done for the Shimokubo block of Yuzurihara landslide clarifies the method of seepage simulation.

\section{Case study (The YUZURIHARA Landslide, Shimokubo block)}

Based on the results of the parametric analysis ex-

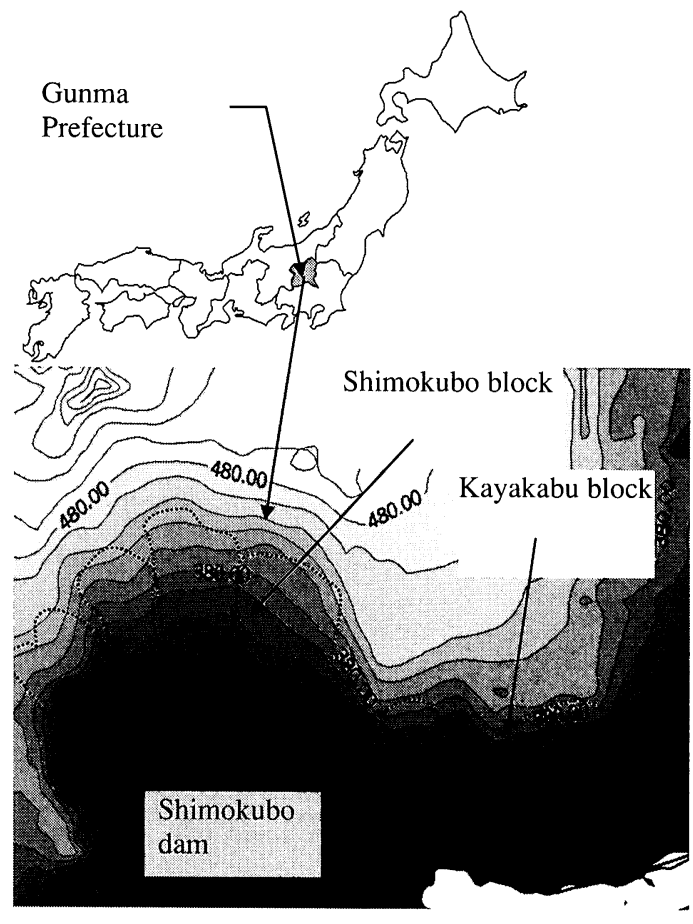

Fig. 14 Location map of the Yuzurihara landslide

plained above, a case study was done to find a suitable seepage model for Shimokubo block of the Yuzurihara landslide. This landslide is situated in Gunma prefecture in the central Japan. Geologically it is located in the Sambagawa formation of middle Jurassic period. It consists of basalt lava, dolerite, hyaloclastite and volcanic rocks. Shimokubo fault line exists at the proximity of the landslide area.

The data and figures used in this article are taken from the reports prepared by the Tonegawa Sabo Office, which is looking after the execution of inspection and construction of countermeasures for the Yuzurihara landslide. Some of the data are obtained from the Sabo Technical Center (STC). According to these reports, this landslide became active in 1910. The landslide has stopped and reactivated several times in the past. Due to reactivating of the landslide in 1938 the local people had to be evacuated. In 1962 it was designated as landslide prevention zone. The investigation and landslide countermeasure planning started in 1991 only.

Fig.14 shows the location map of the landslide. The landslide is divided into two big blocks, namely, Shimokubo block and Kayakabu block. The two blocks are separated by a ridge and are moving independently. These are further sub-divided into different blocks. Various landslide countermeasures were applied to the Kayakabu block, whereas Shimokubo block does not have any major prevention works. Shi- 


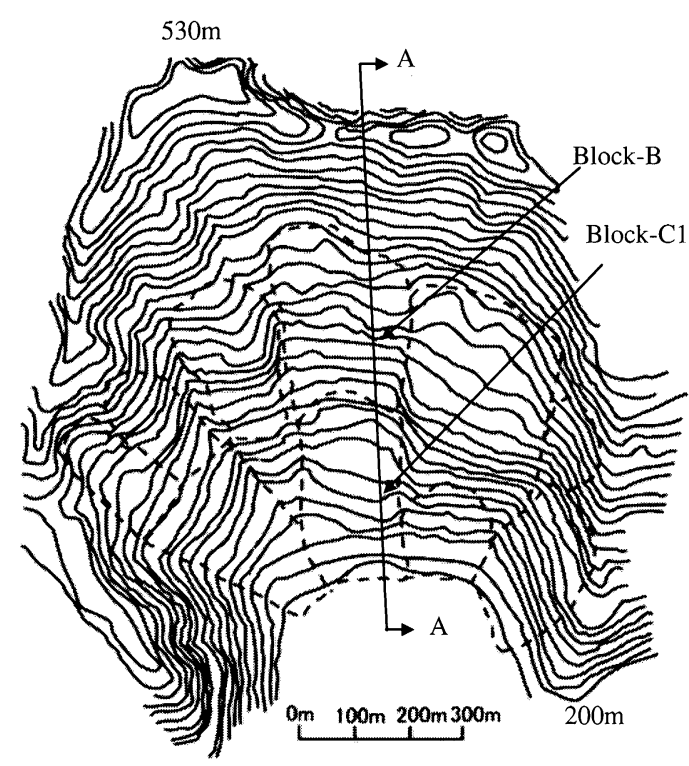

Fig. 15 Topographic map of Shimokubo block

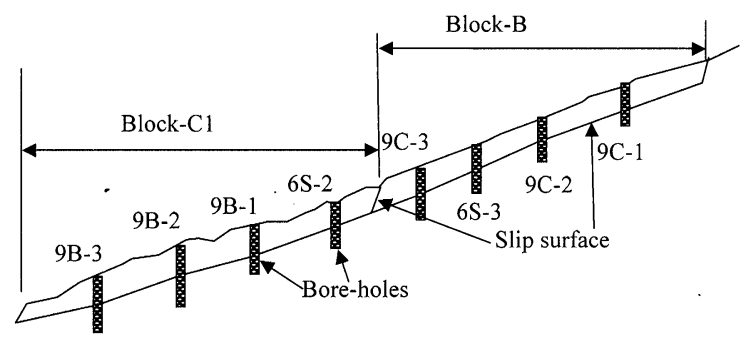

Fig. 16 Cross-section of the landslide block $B C-1$ along A-A

mokubo block was taken for analysis as it was not influenced by construction work. A section along A-A (Fig.15) as shown in the Fig.16 was analyzed. The length and depth of the section is about $500 \mathrm{~m}$ and $25 \mathrm{~m}$ respectively.

A typical boring core shows top layer of clay or silty clay or clay mixed rock fragments. Beneath this, highly fractured rock layer and further below less fractured rock layer exists. The boreholes $9 \mathrm{C}-2,9 \mathrm{C}-3$ and 9 B-3 are being used to measure groundwater level while inclinometers are installed in the other boreholes. Rainfall is being measured daily while groundwater levels at various boreholes are being measured manually once in a week. As can be seen in Fig.17, variation of groundwater level is very small. The difference between maximum and minimum groundwater level is less than $2 \mathrm{~m}$. Even after intense rainfall the fluctuation in groundwater level is not remarkable.

\subsection{Experimental analysis of soil properties}

Experimental data on soil hydraulic properties were available for Kayakabu block only. Samples from borehole made by using jet-foam boring method were used

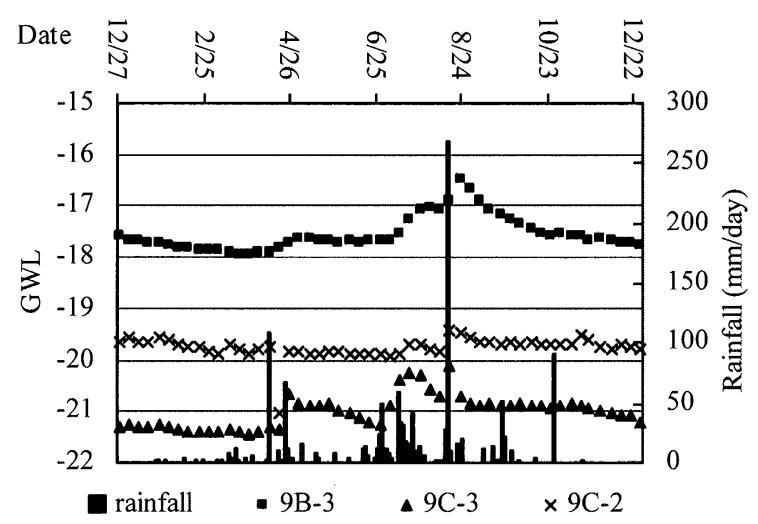

Fig. 17 Groundwater fluctuation in the boreholes

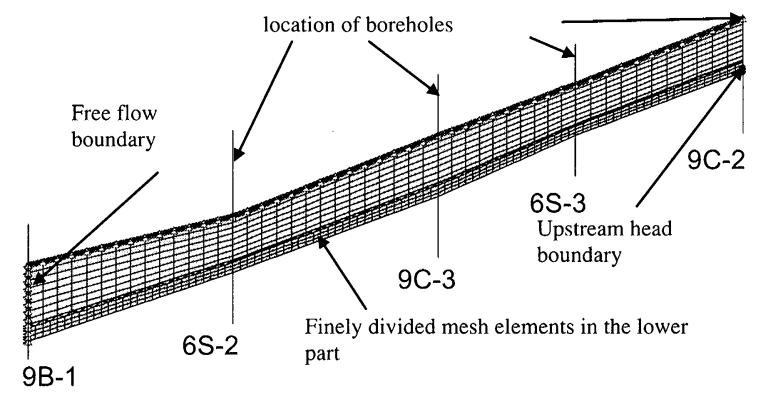

Fig. 18 Finite element mesh for seepage analysis

to measure the soil properties. As the boring cores, obtained using this method, are very little disturbed, the experimental data can be reliable. However, as the boring core had high amount of cracks, only the portions possible to perform experiment was used. The hydraulic conductivity of landslide material varied from $20 \mathrm{~m} /$ day $\left(2.3 \times 10^{-2} \mathrm{~cm} / \mathrm{sec}\right)$ to less than $2.6 \times 10^{-2}$ $\mathrm{m} /$ day $\left(3 \times 10^{-5} \mathrm{~cm} / \mathrm{sec}\right)$. The water retention at saturation and at lowest negative water pressure was less than 0.01 in most cases. This verifies that the landslide materials are too discontinuous.

\subsection{Seepage analysis of the Yuzurihara landslide, Shimokubo block}

Two-dimensional analyses of the models of block B$\mathrm{C} 1$ of Shimokubo block were performed using the results of the above parametric analysis. Fig.18 shows the finite element model of the landslide which represents a portion of the actual cross-section (Fig.16) of the landslide. Few models analyzed with the whole crosssection and a portion of the cross-section produced similar results. Therefore, borehole 9B-1 was considered as the lower boundary. The groundwater level measured at the borehole $9 \mathrm{C}-2$ was input as upstream head boundary. Rainfall and groundwater level of year1999 was used for the analysis. The calculated groundwater level at the borehole 9C-3 was compared with 
the measured groundwater level.

For the initial analysis, the soil was assumed as uniform. The soil hydraulic properties were changed to generate different scenarios. The initial condition for each scenario was obtained by analyzing it with constant average annual daily rainfall of year-1998. Applying the results of the parametric analysis we tried to find the appropriate soil properties. To obtain groundwater level comparable to the actual one, the saturated hydraulic conductivity was varied. Saturated hydraulic conductivity in the range of $1 \mathrm{~m}$ /day was found to produce comparable groundwater level. With this hydraulic conductivity, we varied the water retention function and compared the analyzed groundwater level with actual for each water retention function. The low value of $\theta_{s}-\theta_{r}$ produced higher fluctuation compared to actual and high value of $\theta_{s}-\theta_{r}$ resulted in slow fluctuation compared to the actual. Especially, the high rainfall produces extremely high fluctuation compared to the measured when the value of $\theta_{s}-\theta_{r}$ is small.

In the next step, the top surface of the landslide was considered to have low conductivity. Here, it is necessary to compare with the actual landslide site characteristics. The conductivity data of the Shimokubo block was not available. However, the, experimental data of neighboring Kayakabu block was available. The shape of the ground surface of these two blocks are different, however, but both being colluvial landslide, the properties of the two blocks are similar. The hydraulic conductivity of the top soil is very low in the order of $10^{-2}$ $\mathrm{m} / \mathrm{d}\left(10^{-5} \mathrm{~cm} / \mathrm{sec}\right)$.

With the lowering of conductivity at the top, the groundwater fluctuation becomes slower at the same time the overall groundwater level reduces depending upon the hydraulic conductivity of the surface layer. Therefore, to achieve groundwater level similar to the actual, it is necessary to reduce the hydraulic conductivity of the material 2 (based on the results of parametric analysis, Fig.4). As a result the groundwater level variation becomes very high and the lowest groundwater level becomes much lower than the actual as shown in the Fig.19 Hence, other than reducing the value of hydraulic conductivity it is necessary to find other conditions which lead to increase in the groundwater level without affecting the fluctuation. Here, we considered a low conductivity material at the bottom of the landslide. As the boring core also exhibits less cracks at the bottom layer, such assumption is reasonable. Iteration was revised with this new scenario.

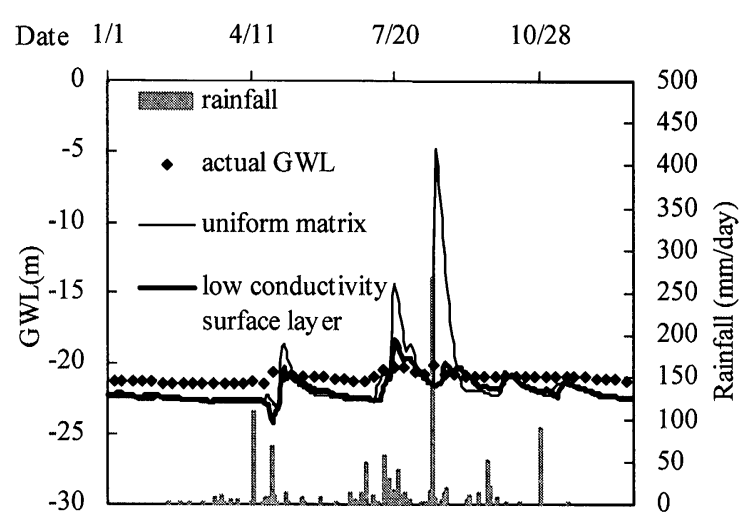

Fig. 19 Variation of groundwater level with and without surface layer

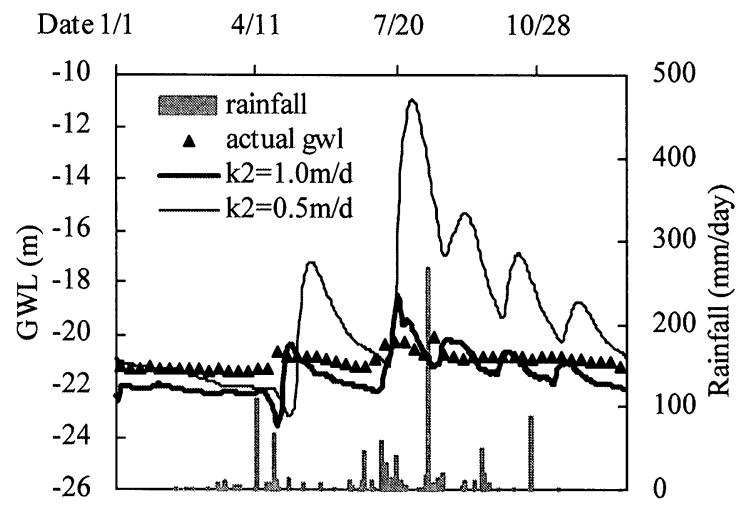

Fig. 20 Result of simulation with different conductivities of bottom layer, two-layered matrix

When the matrix at the bottom layer has low conductivity, the lowest water level maintains higher compared to the result of analysis with two layered arrangement. Also, in the case of two layered arrangement the conductivity of material-2 obtained from the iteration is very high. This shows that the calculated groundwater level is highly affected by fluctuation in the groundwater level at the boundary. The result of calculation with two different hydraulic conductivity of the bottom layer of two layered scenario is shown in Fig.20.

If we consider three layered arrangement the model becomes more complex. The reduction in the hydraulic conductivity of top layer reduces the fluctuation of groundwater (Fig.21). The change in water retention function of the bottom layer does not affect the fluctuation very much. The hydraulic conductivity function of the bottom layer soil also does not have big effect as far as it is much lower compared to the matrix below top layer (corresponding to Material 2, Fig.10). The conductivity and the water retention function of the bottom material do not affect the result noticeably. 
Based on these observations, further simulation models were analyzed. The depth and material properties of all the three layers were varied to obtain the calculated groundwater level similar to the measured groundwater level. Hydraulic parameters of the model which produced the best result in the analysis are shown in Table 3 and corresponding graph is shown in Fig.22.

\section{Conclusions}

The present research is aimed at finding appropriate method for simulation of groundwater flow with seepage simulation software using the result of parametric analysis. We analyzed the effect of different parame-

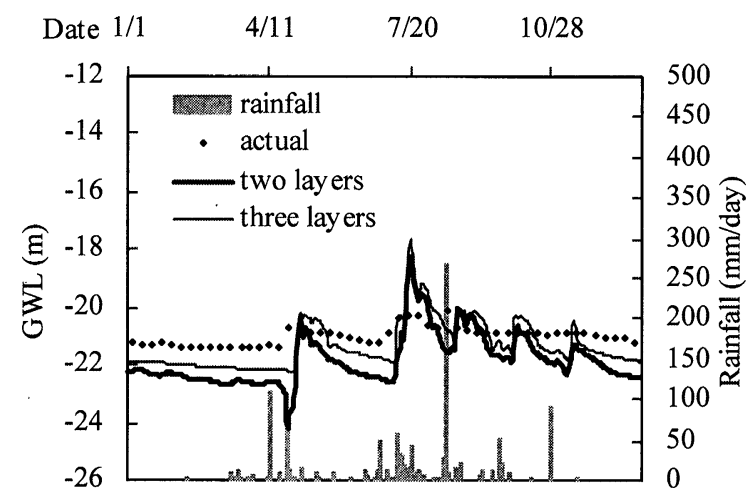

Fig. 21 Typical difference between the simulation results of two-layered and three-layered scenarios

Table 3 Hydraulic parameters of landslide materials

\begin{tabular}{|l|c|c|c|c|c|}
\hline Layer & $\begin{array}{c}\text { Average } \\
\text { depth }(\mathrm{m})\end{array}$ & $\begin{array}{c}\mathrm{k}_{\mathrm{s}} \\
(\mathrm{m} / \text { day })\end{array}$ & $\begin{array}{c}\mathrm{k}_{\mathrm{r}} \\
(\mathrm{m} / \text { day })\end{array}$ & $\theta_{\mathrm{s}}$ & $\theta_{\mathrm{r}}$ \\
\hline Top & 4.5 & $4 \times 10^{-2}$ & $8 \times 10^{-6}$ & 0.347 & 0.255 \\
\hline Mid & 13.5 & 10.0 & $5 \times 10^{-6}$ & 0.347 & 0.340 \\
\hline Bottom & 4.0 & $4 \times 10^{-2}$ & $8 \times 10^{-6}$ & 0.347 & 0.255 \\
\hline
\end{tabular}

ters on the groundwater level and its fluctuation for a single layered and multi-layered matrix systems. The hydraulic conductivity function of each layer controls the usual groundwater level while the pattern of fluctuation of groundwater level is attributed to the soilwater retention function.

From the present analysis we could understand that to maintain low groundwater level, the hydraulic conductivity of the landslide material must be relatively high. When the landslide material has conductivity high in the range of $1 \mathrm{~m} / \mathrm{d}\left(10^{-3} \mathrm{~cm} / \mathrm{sec}\right)$, the fluctuation of groundwater is relatively slow unless the water retention capacity $\left(\theta_{s}-\theta_{r}\right)$ of the material is low.

Further, a landslide possessing high conductivity and low water retention capacity shows very high fluctuation in groundwater level. The rise in groundwater level can be more than $10 \mathrm{~m}$ especially in the case of high rainfall. The low-conductivity surface layer restricts the infiltration of rainfall causing fluctuation of groundwater level diminish. Further, the bottom layer with lower amount of cracks acts as a barrier to the further penetration of the seeping water.

The Yuzurihara landslide can be taken as a typical landslide in fracture zone. The surface soil layer consists of colluvial soil composed of clay or clayey silt beneath which highly weathered and fractured rock exists. The bed rock is also slightly weathered and fine cracks can be seen on the pictures of boring core. The present analysis can be applied to the other fracture zone landslides of similar characteristics.

In the present analysis, all the parameters including the depth of different materials were, to an extent, unknown. However, if we know the depth and hydraulic properties of surface layer it will be easier to do seepage simulation to find the soil properties of the layer beneath the surface layer. Based on the present re-

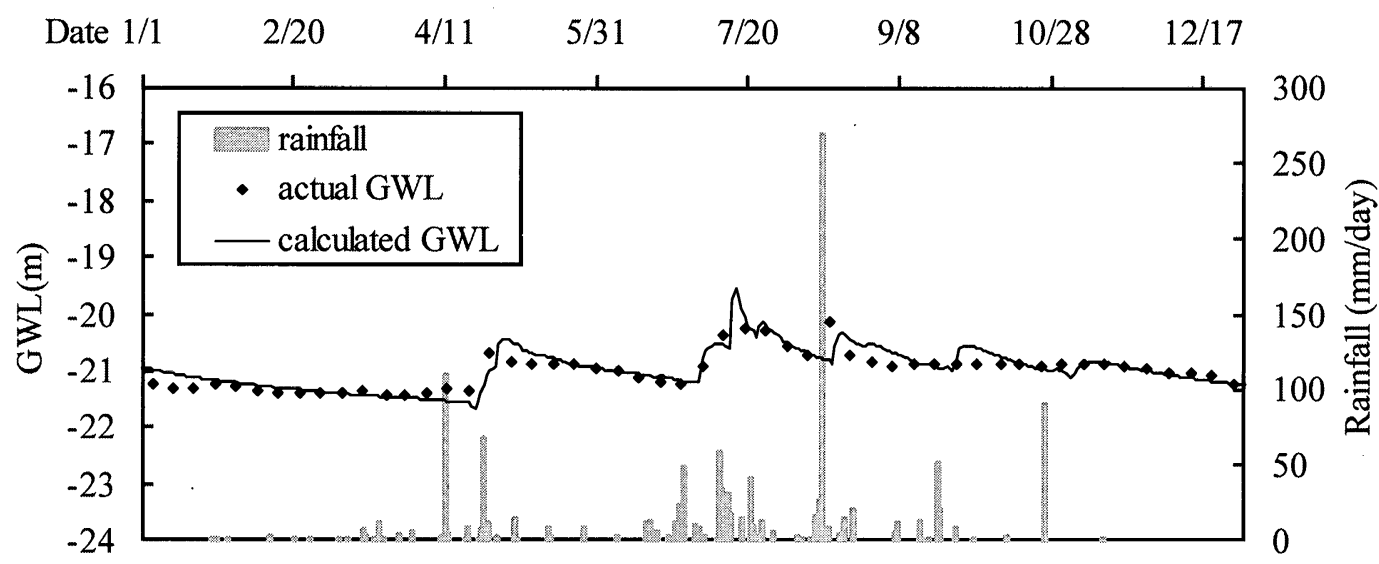

Fig. 22 The model showing the best comparison with the actual groundwater level 
search we can recommend undertaking more experimental works regarding soil properties of the surface layer.

The results of analysis can be further verified and supported by the borehole data. However, the borehole log does not suffice to interpret the exact depth of different layers and the other material properties. Hydraulic properties of the surface layer and the layer beneath it, which is the most conductive layer, play a major role in groundwater fluctuation.

\section{Acknowledgements}

We are grateful to Mr. Hidehiko Manzen, chief of the Tonegawa Sabo Office and all its staffs for providing the data and reports related to the Yuzurihara landslide. We also acknowledge the Sabo Technical Center for providing various data.

\section{References}

1) Brooks, R. H., and Corey, A.T.(1964): Hydraulic properties of porous media, Hydrology Paper No.3, Colorado State Univ. $27 \mathrm{p}$.

2 ) Burdine, N.T.(1953) : Relative permeability calculation from pore-size distribution data, Transactions of the American Institute of Mining Metallurgical, and Petroleum Engineers, Vol.198, pp.71-78.

3 ) Caine, N.(1980): The rainfall intensity-duration control of shallow landslides and debris flows, Geografiska Annaler Series A62, pp.23-27.

4) Cannon, S.H. and Ellen, S. (1985) : Rainfall conditions for abundant debris avalanches, San Francisco Bay region, California. California Geology 38(12), pp.267-272.

5 ) Cho, S. E. and Lee, S. R.(2001) : Instability of unsaturated soil slopes due to infiltration, Computers and Geotechnics, Vol.28, pp.185- 208.

6 ) Duggid J. O. and Lee P.C.Y.(1977) : Flow in fractured porous media, Water Resources Research vol.13, pp.558-566.

7 ) Durner, W., Priesack, E., Vogel, H. J. and Zurmuhl, T. (1999) : Determination of parameters for flexible hydraulic functions by inverse modeling, Characterization and measurement of the Hydraulic properties of Unsaturated Porous media, University of California, Riverside, CA, pp.817-829.

8 ) El-Naqa, A. (2001) : The hydraulic conductivity of the fractures intersecting Cambrian sandstone rock masses, central Jordan, Environmental Geology, Vol.40, pp.973-982.

9 ) Fell, R., Chapman, T.G. and Maguire, P.K.(1991) : A model for prediction of piezometric levels in landslides, Slope stability engineering, pp. $37-42$.

10) Furuya, T. (1982) : On some characters of the so-called fractured zone type landslides, Landslides-Journal of Japan Landslide Society, Vol.18 No.4, pp.54-58 (In Japanese).
11) Gasmo, J. M., Rahardjo H. and Leong, E. C.(2000) : Infiltration effects on stability of a residual soil slope, Computers and Geotechnics, Vol.26, pp.145-165.

12) Greco, R. (2002) : Preferential flow in macroporous swelling soil with internal catchment: model development and applications, Journal of Hydrology, Vol.269, pp.150-168.

13) Hendrickx, J.M.H. and Flury, M. (2001) : Conceptual Models of Flow and Transport in the Fractured Vadose Zone, National Research Council, National Academy Press, Washington, DC, pp.149- 187 .

14) Jakob, M. and Weatherly, H.(2003) : A hydroclimatic threshold for landslide initiation on the North Shore Mountains of Vancouver, British Columbia, Geomorphology, Vol.54, Issues3 -4 , pp. $137-156$

15) Koide, H.(1955) : The Japanese landslides-prediction and countermeasure, Toyo Keizai Incorporated publications, page 259 (In Japanese)

16) Mualem, Y.(1976) : A new model for predicting the hydraulic conductivity of unsaturated porous media, Water Resources Research, Vol.12, pp.513-522.

17) Ng, C.W.W. and Shi, Q.(1998) : A numerical investigation of the stability of unsaturated slopes subjected to transient seepage, Computer and Geotechnics, Vol.22, pp.1-28.

18) Or, D. and Tuller, M.(2003) : Hydraulic conductivity of partially saturated fractured porous media: flow in a crosssection, Advances in Water Resources, Vol.26, pp.883-898.

19) Reports prepared for Yuzurihara landslide examination committee (various years), Ministry of Construction, Tonegawa Sabo Office and Sabo Technical Center (unpublished, in Japanese).

20) Richards, L.A.(1931) : Capillary conduction of liquids through porous mediums, Physics $1: 3$, pp.18-333.

21) Simunek, J., Nick, Jarvis, J., van Genuchten, M. Th. and Gärdenäs A.(2003) : Review and comparison of models for describing non-equilibrium and preferential flow and transport in the vadose zone, Journal of Hydrology, Vol.272, Issues1-4, Pages 14-35.

22) Sobieraj, J. A., Elsenbeer, H. and Cameron, G. (2003) : Scale dependency in spatial patterns of saturated hydraulic conductivity, CATENA, In Press.

23) Tsaparas, I., Rahardjo, H., Toll, D. G. and Leong, E. C, (2002) : Controlling parameters for rainfall-induced landslides, Computers and Geotechnics, Vol.29, pp.1-27.

24) van Genuchten, M.T.(1980) : A closed form equation for predicting the hydraulic conductivity of unsaturated soils, Soil Science Society America Journal, Vol.44, pp.892-898.

25) Vogel, H.J. and Roth, K. (2003) : Moving through scales of flow and transport in soil, Journal of Hydrology, Vol.272, pp.95- 106

26) Wieczorek, G.F.(1987) : Effect of rainfall intensity and duration on debris flows in central Santa Cruz Mountains, California. Reviews in Engineering Geology VII. 93-104.

27) Wieczorek, G.F., Morgan, B.A. and Campbell, R.H.(2000) : Debris flow hazards in the Blue Ridge of Central Virginia, Environmental and Engineering Geoscience 6(1), 3-2.

(Received January 7, 2004, Accepted April 19, 2004) 